\title{
The personal versus the institutional voice in an open photographic archive
}

\author{
Karin Wagner $^{1}{ }_{(\mathbb{B})}$
}

Published online: 13 January 2017

(C) The Author(s) 2017. This article is published with open access at Springerlink.com

\begin{abstract}
In an open photographic archive where both archival institutions and the general public can upload images and provide them with descriptions, a noted difference can be perceived between the institutional voice and the personal voice. Private persons' written descriptions of their photographs tend to have a more subjective style than the neutral, objective style of descriptions written by institutional staff influenced by archival guidelines. Seven examples from the site Historypin will be analysed using semiotics, rhetoric and genre theory as theoretical approaches. Deixis is a key concept in the analyses. In order to discern the institutional voice, meta-genre documents like archival guidelines have been studied. Regarding the personal voice, it is shown how genres that evolved long before the web serve as patterns for the contributions to Historypin, and at the same time how these genres undergo a renewal in this context. The article concludes by suggesting ways the personal voice could be strengthened and that institutions might benefit from creating fictional stories emulating the personal voice.
\end{abstract}

Keywords Photography $\cdot$ Deixis $\cdot$ Genre $\cdot$ Social media Voice $\cdot$ Finding aids

\section{Introduction}

Not only do many public photographic archives make their collections available on their own websites, they also try to reach out to a wider audience at photographysharing sites and social media sites. Some of these sites allow the general public to contribute their photographs as well, which can result in a heterogeneous collection

Karin Wagner

karin.wagner@gu.se

1 Department of Cultural Sciences, University of Gothenburg, Box 200, 40530 Göteborg, Sweden 
of images and a clash between different types of voices that are created by the combination of images and texts.

Social media has contributed to shaping a participatory culture (Bruns 2008) that has broadened the perception of cultural heritage and made it possible for more people to engage in the creation and preservation of cultural heritage (Giaccardi 2012). Institutions can gather information about the material from the audience, and in this way enrich the collections (Kalfatovic et al. 2008). One specific initiative to spur interest in history among the general public and provide a way for cultural heritage institutions to increase the exposure of their collections and archives is Historypin, a website developed by the social enterprise Shift in partnership with Google. As it says on the homepage: "Historypin is a place for people to share photos and stories, telling the histories of their local communities". ${ }^{1}$ This initiative goes further than for instance Vele Handen, a crowdsourcing website that invites people to contribute information about collections of cultural heritage institutions. Historypin not only allows the general public to provide information about existing content, but also to participate in the creation of new content. Historical photographs can be uploaded to the site and pinned to a map and even form mashups if overlaid onto Google Street View. Not only institutions, but also private persons can create their own "channel" where all their photographs will appear. Some thematic collections have been created, but the main search method is through the map. It is the geographical place that is the focus of this site, and both institutions and private persons are thus involved in forming the historical image of a certain place or area. This entails that an official museum record can be found at the same spot as an unknown family snapshot with idiosyncratic metadata not compliant with any archiving standard. Private persons' written descriptions of and stories about their photographs convey memories, emotions and associations that the pictures evoke for them and tend to have a far more subjective style than the neutral, objective style of descriptions produced by institutional staff.

Historypin questions the idea of archival holdings. It might be regarded as an archive in its own right, where the private contributions form one part, or just as a showcase for physical archives. In Historypin the vast official archive meets the shoebox, the one time pinner the bulk uploading institution, the amateur the professional archivist. As I browsed through the Historypin collections, I realized that, whereas the image descriptions made by professionals are similar in style, there are quite a number of different approaches taken by private persons, something that determines the perception of the images.

It is the cultural clash between the personal voice and the institutional voice that is the subject of this paper. The clash highlights the constructed character of the institutional voice of the archival description that is so prevalent that it has been taken for granted and regarded as natural.

What constitutes and characterizes the personal voice in contrast to the institutional voice in an open photographic archive? How do private persons combine image and text to form a personal voice? These are the key questions that will be explored.

\footnotetext{
${ }^{1}$ www.historypin.com Shift was formerly known as We Are What We Do.
} 


\section{Theoretical approach}

The study will involve both textual and visual components and how they relate to each other. Several theoreticians have written about the relationship between word and image in the context of art and the literature (Bal 1991; Mitchell 1996; Elkins 1998). Others have directed their attention specifically to the relationship between word and photograph in the context of advertizing and news media, discussing how the meaning of photographs can be "anchored", secured or restricted by captions and other textual elements (Barthes 1964; Sontag 1977; Scott 1999). I will mainly draw on rhetoric, genre theory and semiotics. These theories overlap and are often combined in various constellations; Barthes (1964) laid the foundation for visual semiotics with his essay "The rhetoric of the image" and rhetorical genre theory is, as its name suggests, a combination of rhetoric and genre theory. However, for the sake of clarity, they will be dealt with under separate headings below.

\section{Rhetoric}

Rhetoric is the art of persuasion through eloquent speech, but the field of study includes different forms of communication (Knape 2013). Orality is a concept with pertinence both to traditional ways of viewing and photographs and to the new viewing and sharing practices of the digital age. Ong (1982) minted the concept secondary orality to denote how orality evolves in the presence of technologies such as the printing press, the telephone and television. Secondary orality can take the form of audiobooks, pre-written speeches, and has thrived in the digital age through text messaging and social media communication. It depends on written language, but occurs in the present moment and can foster a sense of community like orality before written language (Ong 1982, p. 132). In the context of archives, Hugh Taylor suggested that computer technology would entail a conceptual orality, emphasizing the context of a document and the action that gave rise to it, rather than the document itself (Taylor 1987, 1988).

Secondary orality is highly relevant for the analysis of the use of images in new media (Wagner 2011). In his study of family albums, Chalfen (1987) concluded that viewing family photographs belongs to an oral tradition where stories are told, not written. When this "home mode" is transferred to a web context, the storytelling can occur through both visual and textual means. Martha Langford states in Suspended conversations: "The showing and telling of an album is a performance", and she suggests that Barthes hears himself and his voice in his "intimate literary performance" of Camera lucida (Langford 2001, p. 5). The narrow circle of audience for the family album presentation or for the contemplation of one treasured image is considerably widened when it comes to presenting personal photographs on websites such as Historypin. Still, some of the traits of practices around the family album can be discerned. 


\section{Genre theory}

Originating from literary studies, genre is a concept commonly used to categorize literary works as well as musical pieces, films or images that share common characteristics of form or content. However, according to John Frow “...genres actively generate and shape knowledge of the world" (Frow 2015, p. 2). Frow's conception of genre lies close to Foucault's discourse and involves speaking positions, social dimensions and questions of power. There is a dynamic relationship between genres that makes them change and take on new functions. Genre should not primarily be seen as a stylistic device apt for classification, but as a formal structure that works at a deeper level of a text (Frow 2007).

In order to show how the negotiation of genres is at work in Historypin, I will turn to rhetorical genre theory, a perspective that will be helpful for distinguishing not only between the personal and the institutional voice, but also between different personal voices. For rhetorical genre theory Mikhail Bakhtin's essay on speech genres (Bakhtin 1986) and Carolyn Miller's article on genre as social action (Miller 1984) have been especially influential. Both criticized genre studies for being too formalistic, which did not mean that they were neglecting form-instead, they saw form as an integral aspect of genre, but felt the need to emphasize the communicative contexts in which genres are shaped (Devitt 2009). In the literature on genres in the digital realm, the online diary is an example of a genre that has attracted some attention. Laurie McNeill (2005) discusses how the diary and the blog interact and evolve as genres, and how readers and writers handle the shifting demands. Conventions and expectations are the main elements of a genre model proposed by Lüders et al. (2010). Having made studies of online diaries and camphone self-portraits they conclude that users learn from existing genres. They also discuss the distinction between genres and media and argue that the blog should be regarded as a medium rather than a genre. This classification is contested by other researchers who view the internet as a medium, which comprises blogs, chats, homepages and other genres (Lomborg 2011).

In the field of archival science, there is an increased awareness of the relevance of genre studies (Oliver and Duff 2012). The demands placed on archival institutions for catering to the needs of new types of users in the digital age have given rise to research on the role and design of finding aids and archival descriptions. According to Joan Schwartz, finding aids for photography collections in Canada were originally created by archivists for their own use (Schwartz 2002). In applying a rhetorical genre perspective to these text types Heather MacNeil writes:

Archival finding aids both shape and are shaped by professional perspectives of reality and, in so doing, could be said to participate in the construction of a discourse community comprising archivists and users of archives. In order to become members of that discourse community, both archivists and users must acquire background knowledge of finding aid conventions and archival descriptive practices. (MacNeil 2012, p. 492) 
Description standards and archival guidelines are regarded as a meta-genre that determines how archivists work with descriptions. An emerging meta-genre is the moderation protocols necessary for managing the crowdsourcing contributions that form part of the participatory culture of culture heritage (MacNeil 2012). The objective style of descriptions fostered by such guidelines is also prevalent in the genre of historiography at large, according to Cayce Myers and James F. Hamilton. They regard social media as a genre in its own right, with a potential of democratizing history writing (Myers and Hamilton 2015).

\section{Semiotics}

In his analysis of the Italian food advertisement in "The rhetoric of the image" and in later essays Barthes developed the semiotic concepts of denotation and connotation: denotation for what is literally shown and connotation for all the associations that this object brings with it (1964). There are other concepts as well from the semiotic toolbox that will be fruitful for the analysis of the material at hand. The concept of deixis will be deployed for demonstrating how users refer to their pictures by figuratively pointing to them in their descriptions. Deixis denotes ways of using language that is context dependent and relative to the person making the statements. Personal pronouns like "I", "me", "we" (person deixis) and adverbs like "now" (time deixis), "here" and demonstratives like "this", "that" (place deixis) are used to refer to something that is possible for others present in the situation to perceive. Often the statements are combined with gestures or glances pointing to the object or phenomenon at hand. The point of reference, or the deictic centre, is called origo, which often coincides with the person making the statements (Levinson 2004; Bühler 1934).

Martinec and Salway (2005) have examined the image text relations in media by combining theories from Roland Barthes and the linguist Michael Halliday. The latter's logic-semantic relations and status relations have bearing on how the photographs interact with text in my material, especially the concept expansion, which can be broken down into extension, enhancement and elaboration. These concepts help clarify how an accompanying text can add new information (extension) to a picture, make it more precise in terms of for instance time and place (enhancement) or provide more detailed information or comment on it (elaboration).

Halliday's theories have also been a source of inspiration for the multimodal version of social semiotics elaborated by Kress and van Leeuwen (2006). In a web context, the interface is important for the interpretation of the images. Like print media, webpages made by professional web designers or with the help of generic website templates share a consistent structure and a layout that governs the meaning making process of the reader (Kress and van Leeuwen 2006). Articles by Historypin institutional users stress this aspect of the site. At the University of Saskatchewan, the library uploaded part of their postcard collection and found that the Historypin interface facilitates the connection between the written description and the image: "The history of the item is not simply hidden among the rest of the metadata in a sometimes overwhelming list, but takes a central role in interpreting the item" (Harkema and Nygren 2012, p. 6). Another study from the University of Tennessee 
revealed that material uploaded to Historypin was viewed and explored to a much higher extent than in the library's own website, which was probably due to the mapbased interface of Historypin and that people who are interested in historical photographs gather at the site (Baggett and Gibbs 2014). However, as the interface is not an important factor regarding the difference between the personal and the institutional voice, it will only be briefly analysed in this article.

\section{Methodological reflections}

Pinning a picture to Historypin requires three pieces of metadata: title, date and place. One can further give a short description, which will appear to the right of the image on the published webpage. It is mainly this description that I will use in my analysis. In 2015, Historypin contained around 3,50,000 images. To make a systematic selection from such a vast material is difficult, since getting a complete overview is unrealistic. I have followed the site regularly since its inception in 2010. The strategy I have used has been browsing both institutional and private persons' channels publishing in English. I have also browsed the archive through choosing places on the map, prioritizing big cities like London and New York and the capitals of the Nordic countries. In addition, I have collected random samples from less densely populated areas. I have also practised pinning myself and created a small collection.

Apart from studying Historypin, in order to discern traits that characterize the genre of archival description, I have scrutinized some meta-genre documents like cataloguing guidelines as well as archival records on the websites of some of the institutions supplying material to Historypin. In this way I have endeavoured to find a base for the institutional voice. The starting point for my study was $\operatorname{ISAD}(G)$ : International Standard Archival Description (General) (2000), and I subsequently selected guidelines from major institutions with large image holdings: Descriptive Cataloging of Rare Materials (Graphics), DCRM(G) of the Library of Congress (2013), Guidelines for efficient archival processing in the University of California Libraries (University of California Libraries 2012) and Basic Guidelines for Minimal Descriptive Embedded Metadata in Digital Images from the Smithsonian Institution (2010). Standardization, searchability, clarity and objectivity are keywords in all the documents I have studied. The guidelines for metadata in digital images from the Smithsonian Institution state: "The more standardized and useful information we put into the metadata, the more searchable these images" (Smithsonian Institution 2010, p. 2). The Descriptive Cataloging of Rare Materials (Graphics) (Library of Congress 2013, s. 1F2.1) advises how to supply a title to an image: "For untitled images of a documentary nature, give the objective factual content clearly and concisely", and how to write a summary: "Give a brief objective summary of the content, meaning, or iconography of the material, if not apparent from the body of the description" (Library of Congress 2013, s. 7B1).

The users of Historypin also have access to manuals and how-to videos about the procedures of uploading and pinning photographs. These guides can be regarded as a "Historypin meta-genre". In the video "How to pin a photo" (2011) there is a 
screen shot of the form that users need to fill in. Metadata required are title, date and place, whereas entering keywords and other information is optional. The prompt for the description field is "What's the story?" The voice over says: "You can also add the story behind the photo". In a manual in pdf-format, Historypin User Guide (2013), the label of the field has been changed to Description. In January 2016, a new instruction video, How to add a pin to Historypin (2016), encourages the pinner uploading a photograph to "describe the story behind it". In July 2016, when I last pinned a photograph myself, the prompt for date was "When is this from?", and for place "Where is this from?". The field for description was prefilled in grey with a suggested story: "I took this photo in 1953 when we had one of wettest winters and the village flooded. The waters were so deep that everyone was using boats to get around-this is our vicar in a boat outside the local corner shop". My interpretation of this ambivalent use of terminology is that prompts in the form of questions create more of an "informal" dialogue and less of a "formal" form. "What's the story?" could encourage the user to tell about the photograph in a more open way, whereas Description could result in a literal description of what is seen in the picture. As Description is not a required entry, users apparently could need a push in the form of a suggested story. A comparison of the Historypin instructions with $\operatorname{ISAD}(\mathrm{G})$ reveals some striking similarities concerning required fields as well as the use of examples, although Historypin uses a popular address and informal language. The terminology and examples used for instructing users certainly influence the way they go about the task of describing their pictures, their style of writing and the content of their descriptions/stories. The Historypin guides can be seen to educate the users in a way similar to how archival guidelines train archivists-in both cases the guidelines shape the notion of what archiving means.

\section{The photographs: examples from Historypin}

The contributions made by the general public mostly consist of personal photographs, a broad category that includes photographs taken by amateurs, postcards, family snapshots, class photographs and portrait photographs commissioned from professional photographers - in short, photographs that relate to personal life. With the advent of social media and practices such as taking selfies, the concept of personal photography has gained new meanings, along with the shift of the public/private border (Bate 2016). The photographs posted on Facebook, for instance, can be seen as a kind of personal documentation, which convey stories of peoples' lives and which should be considered as cultural heritage (Sinn and Syn 2014).

Of the seven examples I have chosen from Historypin's database, one represents the institutional voice, the others represent the personal voice. This is not to say that the institutional voice is without variations, but for the purpose of this article the characteristics of the institutional voice are sufficiently brought out in the one example I have chosen. The photographs included range from 1915 to 2012. The objects of study are the images, the descriptions and the combination of the two, and the emphasis will shift between them, concerning what elements help constitute the voice. 
Until October 2015, when a user clicked on a hotspot found on the map, a photograph was displayed in a pop-up window with a layout that resembled a physical archival record, where the photograph is placed at the left-hand side and the description to the right. The illustrations for this article consist of screenshots of these "records". In a new version of the site launched in October 2015, the layout has been altered. The photograph is now much larger, and the description has been placed underneath the photograph.

The image of a streetscape (Fig. 1) has been pinned by London Metropolitan Archives. The description reads "Finsbury Pavement House, Finsbury Pavement, (now Moorgate Street), showing the effects of blast damage. Handcarts and ladders are in the street with a crowd of men behind. 13 October, 1915". The photographer is unknown, but the image was published by a photography agency, so it can be regarded as belonging to the genre news photography. ${ }^{2}$ The text describes the content of the image, as cataloguing guidelines prescribe. Its style is neutral, objective and matter of fact. The information that the picture shows the effects of blast damage can be considered an extension, but in overall, this description is close to a denotation, one that deals with the literal meaning of a sign. I consider this image and the description to be a good representative for the institutional voice.

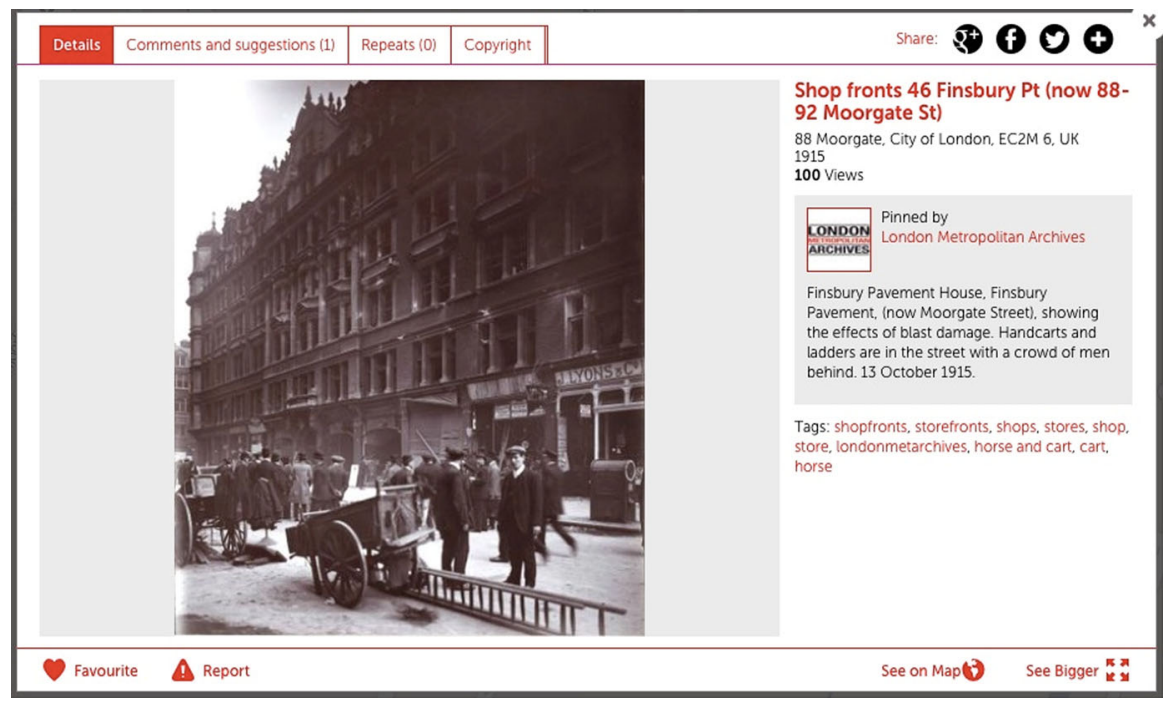

Fig. 1 Shop fronts 46 Finsbury Pt (now 88-92 Moorgate St). (C) City of London, London Metropolitan Archives City of London, London Metropolitan Archives. Added to Historypin: Tue 28 Jun 2011. https:// www.historypin.org/en/person/11752/explore/geo/51.502772,-0.063675,10/bounds/51.269661,-0. $315674,51.734696,0.188324 / \mathrm{pin} / 22820$. Accessed 10 Oct 2016

\footnotetext{
${ }^{2}$ In the database of London Metropolitan Archive, it says "[anon. phot. published by] Miles and Kaye Legal and technical photographers". The description reads "Finsbury Pavement House, Moorgate Street, showing the effects of blast damage. Handcarts and ladders are in the street with a number of men behind. No.41 of a set of 57 photographs showing damage caused by German Zeppelin raids. black and white $292 \times 244 \mathrm{~mm}$ (work)." Hence, the description is virtually the same as in Historypin, aside from the last sentence that has been omitted, probably due to the fact that the whole set is not published in Historypin.
} 
There is an absence of personal pronouns, deictic markers like "This picture shows..." A radically different perception of the image would be caused by the following description: "This photo shows my grandfather, standing to the far right, who saved the lives of three children from the blast".

The next image (Fig. 2) belongs to the same category of streetscapes and buildings as the first one. It was taken in 1984 and pinned by chris.grant. In the description of the channel, the owner states that he has "collected postcards of Portsmouth \& taken photographs (usually just before a building was demolished)". In addition to being an amateur photographer, Grant is a volunteer archivist at Southsea's Kings theatre. The description of the department store begins on the same objective note as the picture from London above, but it ends with “... It was rebuilt in the early 1950's \& served the city well until it was demolished only to be replaced by a third rate shopping mall called the Bridge centre in the late 1980's. From then onwards Fratton Road has been going down hill!" The phrases "third rate" and "going downhill" indicate value judgements, that could be regarded in two ways: as violations of demands for institutional objectivity, or as extra information, an opinion by a citizen who adds value to the image and can be regarded as an extension in the logico-semantic sense. The image shows a building, but the description tells the story about the demolition of a building and the changing face of the city. Instead of finding a description of a static object, in the text we can follow the unfolding of events, a story that starts decades before the photograph was taken and ends long afterwards.

Is this an example of an emerging genre suited for the context of social media and wider audience than the research community? Lüders et al. (2010) argue that new

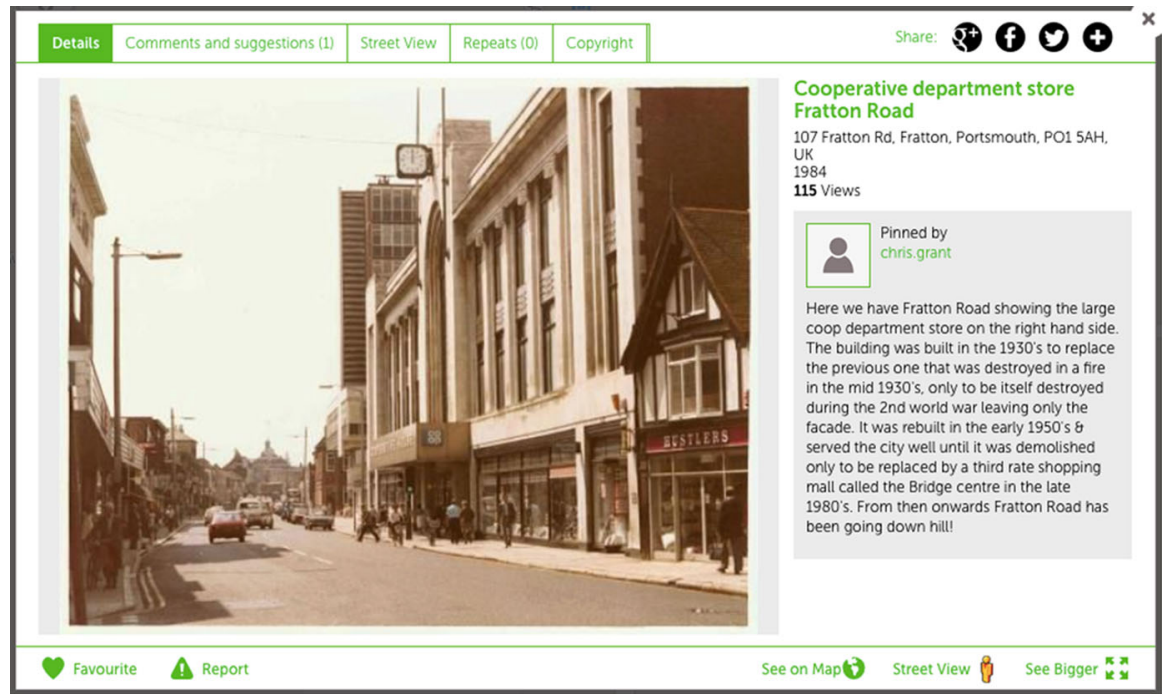

Fig. 2 Cooperative department store Fratton Road. (C) chris.grant. Added to Historypin: Tue 20 Nov 2012. https://www.historypin.org/en/person/2529/explore/geo/51.66276,-1.761734,7/bounds/49.668073,$3.777725,53.573346,0.254257 / \mathrm{pin} / 125968$. Accessed 10 Oct 2016 
genres build on generic knowledge of pre-existing genres. As a volunteer archivist Grant possesses some background knowledge of the archival description genre, sometimes called "archival intelligence" that professional archivists have acquired (MacNeil 2012). The Fratton Road case can be seen as an example of how the personal voice is constructed through the tweaking of the archival description genre. It is debatable whether this photograph can be seen as belonging to the category personal photography, but in this context it certainly represents the personal voice.

The picture (Fig. 3) of St Albans Cathedral in Hertfordshire, UK, is to be found in the channel g.cosserat. The description reads "Taken with my new Box Brownie and developed and printed by myself". It is one out of ten family photographs that appear to have been taken by the pinner around 1953 with the same camera. The subject here is not the building per se, but the photographic process, or rather the memory of having a camera of one's own and being able to take and make photographs. The description can be seen as an example of an enhancement, giving us information about the circumstances of the picture being made. It represents the personal voice - with a different description, for instance "St Albans Cathedral, view from the south", the meaning would have been radically altered and it would have been a representative of the institutional voice. To say that this description violates archival rules is beside the point. It belongs to an entirely different discourse, one that is about personal memories associated with the image. It is likely to have been written in response to the question "What's the story?" from the pinning form filled. Instead of denoting what is shown in the picture, the description is about the connotations of the picture. Both the photograph and its description

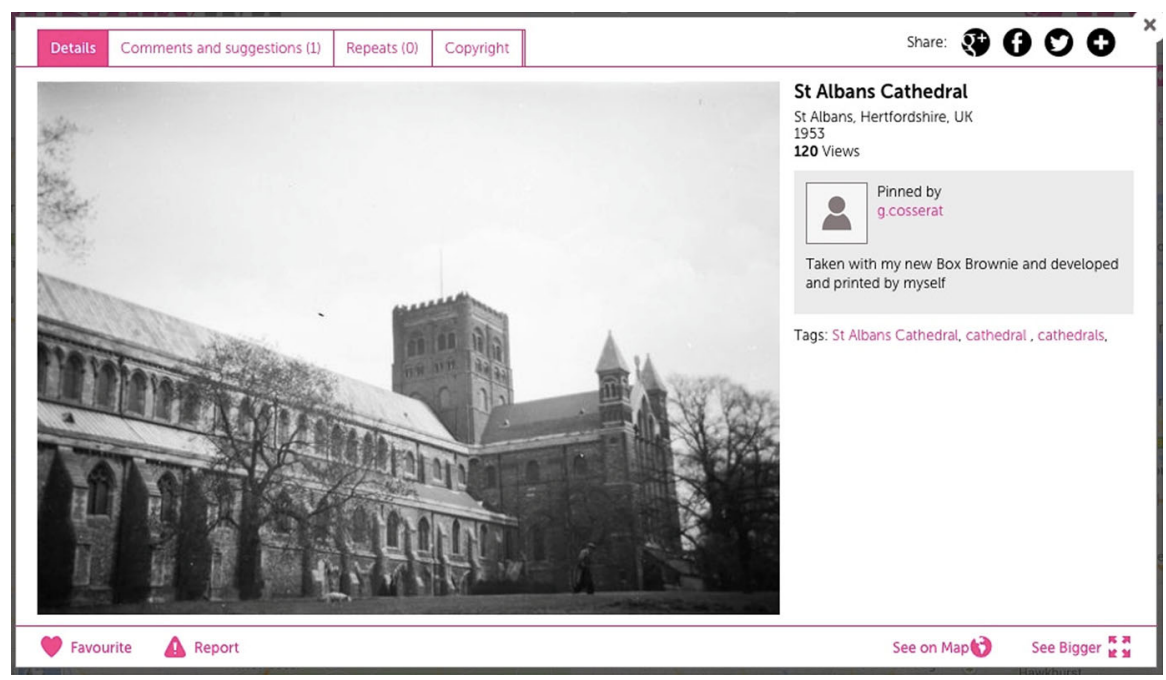

Fig. 3 St Albans Cathedral. (C) g.cosserat. Added to Historypin: Wed 14 Sep 2011. https://www. historypin.org/en/g-cosserat-s-collection/geo/51.139696,-0.306173,5/bounds/42.55507,-8.370138,58. 380094,7.757792/pin/35305. Accessed 10 Oct 2016 
belong to the family album genre. It is an example of how Chalfen's "home mode" has been moved to the web, constructing a personal voice that bears traces of the oral tradition. The text is also deictic in the sense that the user is referring to his camera and his work in the dark room, the deictic origo.

There are several ways a Historypin user can put herself in the picture. I have selected photographs where different strategies are used for making them into personal documents.

A photograph (Fig. 4) taken in 1933 shows an Italian school class of 46 boys and their teacher. The owner of the channel, Angelo Petruccelli, has marked himself with a red circle and the teacher with a green circle.

The class photograph belongs to personal photography; it can be seen as a semipersonal, semi-official document commissioned by an institution but bought by individuals and often included in family albums. Marking oneself with an $\mathrm{x}$ or a circle is common, but marking the teacher in the same way is less common, as the teacher is usually easily distinguishable from the pupils. In this case the teacher plays the main role in the description, which reads: "This is my primary school photograph from 1933. It was the same year that Hitler was made Chancellor of Germany, and my teacher, circled in green, told us it was the first year of darker years to come".

This description is an elaboration and anchors the image in the bigger realm of history and politics not limited to the small world of the classroom. Angelo does not tell us who his best friend was, what became of the other class mates, etc. Instead, his description conjures up a grim future, predicted by the teacher, which forms a contrast to the usual connotations of a class photograph: young people with their whole lives before them, with hopes and expectations. This clashes with the "darker

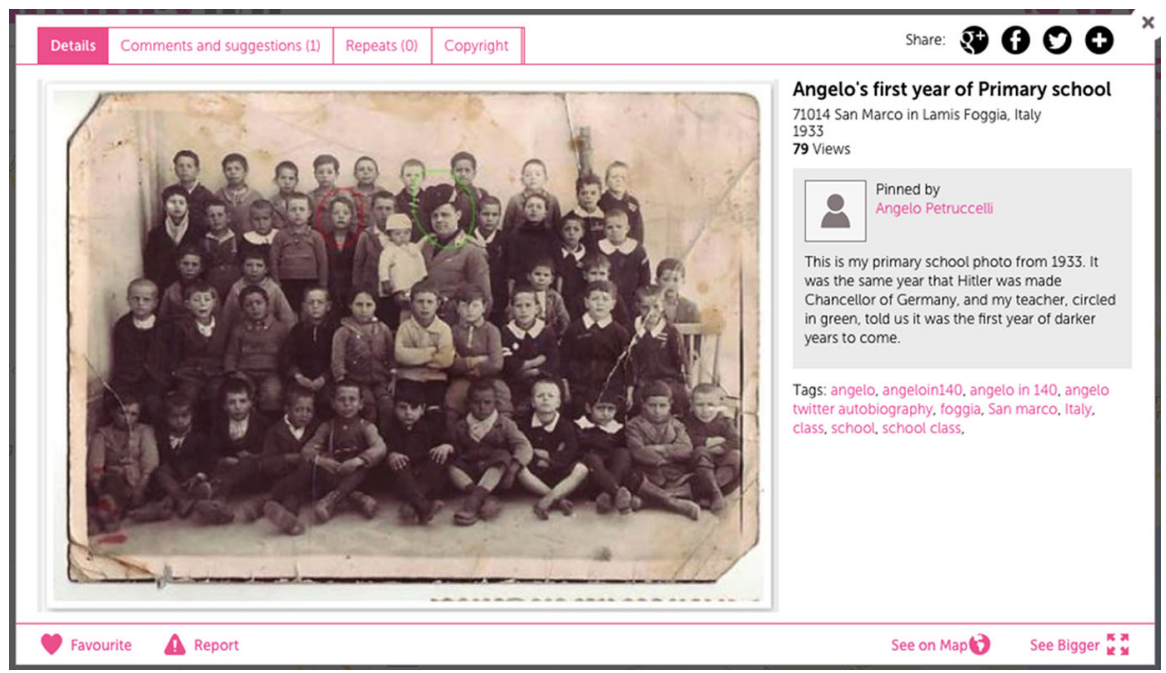

Fig. 4 Angelo's first year of Primary school. (c) Angelo Petruccelli. Added to Historypin: Sun 21 Aug 2011. https://www.historypin.org/en/person/16822/explore/geo/2.491229,84.385081,2/bounds/-69. $585053,19.873362,71.254345,148.8968 / \mathrm{pin} / 30386$. Accessed 10 Oct 2016 
years to come" and creates a tension between the image and the text. The text widens the scope of connotations that this image can evoke. The temporal aspects of the description is interesting from a narratological point of view, since the narrator is both looking back and at the same time facing the future from a position in 1933. With Gérard Genette's terminology the text contains two types of anachronies, both an analepsis (a kind of flashback) and a prolepsis (a kind of flashforward) in an embedded narrative (Genette 1983). By adding this story to the picture, it tips the balance towards the family album genre. Such long explanations might not occur in an album, but it might be part of the oral narrative accompanying a viewing of an album (Chalfen 1987; Langford 2001). In order to tell the story to the larger audience of Historypin, it has to be written down. Here we can discern another attempt to create a new genre, or at least a variation of the family album genre, adapted to the social media context.

A conspicuous quality of this image is the worn state of the photograph, which highlights the materiality of the photograph, often neglected in photographic archives (Edwards 2004). Before Angelo decided to share this photograph with a larger audience through Historypin, the photograph had been handled and folded and possibly displayed in an album judging from the missing corners. The photograph as a material artefact has had a history of its own. As its occurrence in Historypin is a representation of the paper copy, I deem that its worn state should be considered as part of the content of the picture shown in Historypin. It is certainly part of the message this image and its description conveys.

Materiality is also an issue in the next image (Fig. 5), a family photograph from the 1950 s pinned by charlottegoodhart. It is part of a series of family photographs,

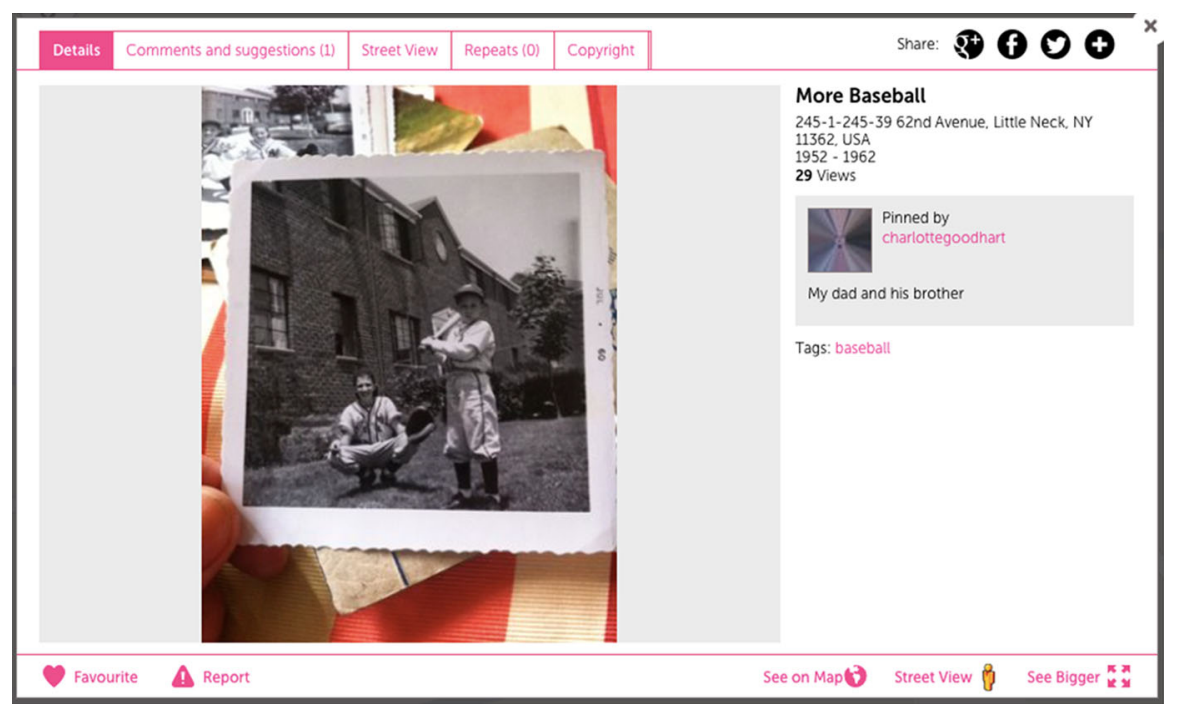

Fig. 5 More Baseball. (C) Charlotte Goodhart. Added to Historypin: Mon 03 Feb 2014. https://www. historypin.org/en/person/45253/explore/geo/43.563241,-60.168495,2/bounds/-46.211425,-124. 680213,81.540678,4.343224/pin/211410. Accessed 10 Oct 2016 
mostly of her father. The description is an enhancement, although a very succinct one: "My dad and his brother", a caption that could appear in any family album.

What distinguishes this photograph from most other family snaps posted in Historypin is the framing of the picture that includes the pinner's hand, the table cloth, albums, envelopes and other photographs in the background. Already the text makes this a personal document, as the phrase "my dad" indicates. Furthermore, the inclusion of the hand can be seen as a partial self-portrait. It also makes the deictic centre visible, the pinner and the deictic gesture she performs, presenting the picture for us to see. The personal voice appears not only in the text, it is here integrated in the image.

This image has two levels of meaning; it is an image of two children and at the same time it is an image of the activity of viewing, sorting and showing photographs. These photographs are brought out in the light, not in an institutional environment, but in a home setting. By including things outside the picture frame, things that are normally deemed as irrelevant and distracting and cropped from the picture, the meaning of this picture has been widened. It is not a question of a "simple" reproduction of an on old family photograph but the documentation of the personal archive revisited. While the old photograph in the image belongs to the family album genre, the image pinned to Historypin does not. What I ask myself is whether this is just an idiosyncratic image with no potential of forming a genre, or if it will indeed do just that.

In the postcard (Fig. 6) with an aerial view of Tahunanui Beach in New Zealand, from 1964, the pinner (channel name: paulsibellas) has marked an area with a circle and an arrow and written: "We used to party at night at the circled area in 1965. Oh Carol, where are you now!" The text evokes past events that occurred in that

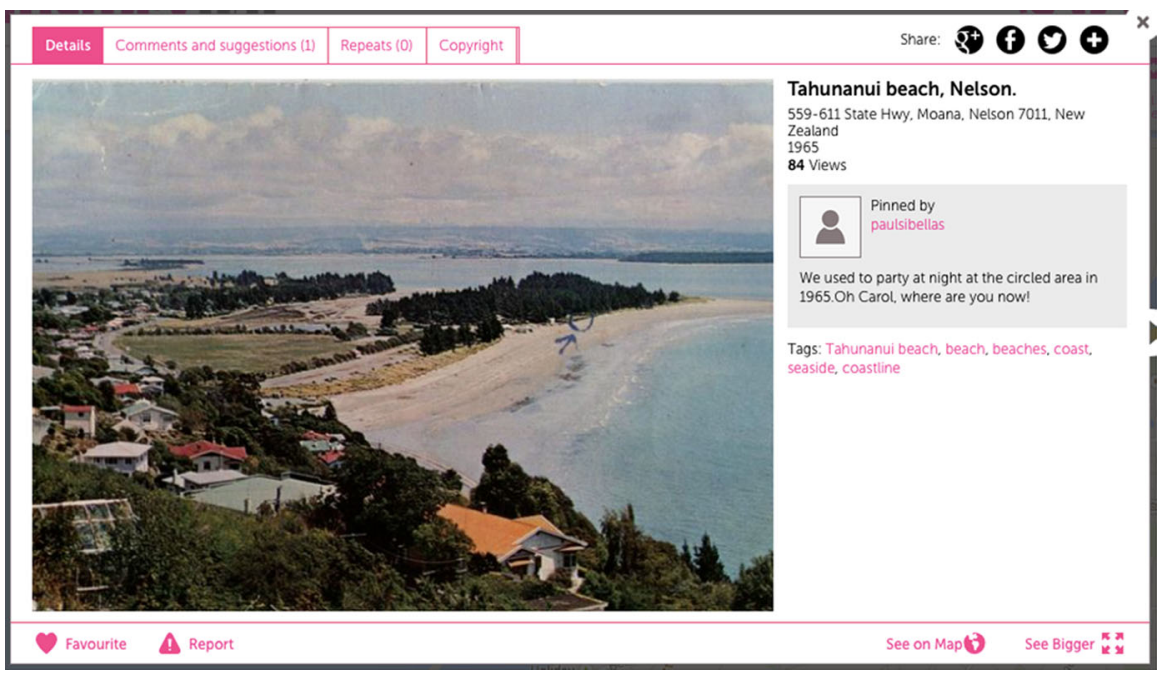

Fig. 6 Tahunanui beach, Nelson. Photograph by Gladys M Goodall. (C) paulsibellas. Added to Historypin: Fri 19 Nov 2010. https://www.historypin.org/en/person/4770/explore/geo/12.280589,87. 477972,2/bounds/-65.845678,22.966254,74.183455,151.989691/pin/12053. Accessed 10 Oct 2016 
particular place that the photograph in itself or a neutral description of what can be seen in the picture would be incapable of bringing forth. It also brings the past time into the present by asking "where are you now?" which can be seen as a rhetorical question but also as a throwing out a message in bottle into the sea of social media; there is a miniscule chance that Carol will actually look for the same spot in Historypin and be reached by the message. Just as in the case of Angelo's class photograph, the personal voice is also constituted by marks on the surface of the photograph. Instead of controlling and fixing the meaning of the image, the text opens up a whole scenario, a wistful story of his youth. It is divided in two short parts - the first informative sentence that could have appeared in a family album, and the second more introvert sentence that could have been taken from a diary. The first sentence is an enhancement, specifying time and place, whereas the second sentence is an elaboration. This and the following image (Fig. 7) are examples of how an image and its description can belong to more than one genre at the same time.

The last picture (Fig. 7) in my selection brings us to the present time. It is a photograph of a building, but it is not meant as documentation of the built environment of Helsinki. It is comparable to a "status update" on Facebook, telling friends and followers what the pinner is up to at the moment, in this case about the visit to Helsinki and the failed attempt to enter the cathedral. The description reads "Built by a Russian designer, one of the biggest Orthodox cathedrals in the Western Europe. The day I visited it is freezing and the church was closed!!!” Just as with the previous image, Tahunanui Beach, the first sentence is an enhancement, and the second an elaboration. The pinner abbela.tao has included her face in the picture, which makes it evident who is talking to us. The text was presumably composed at

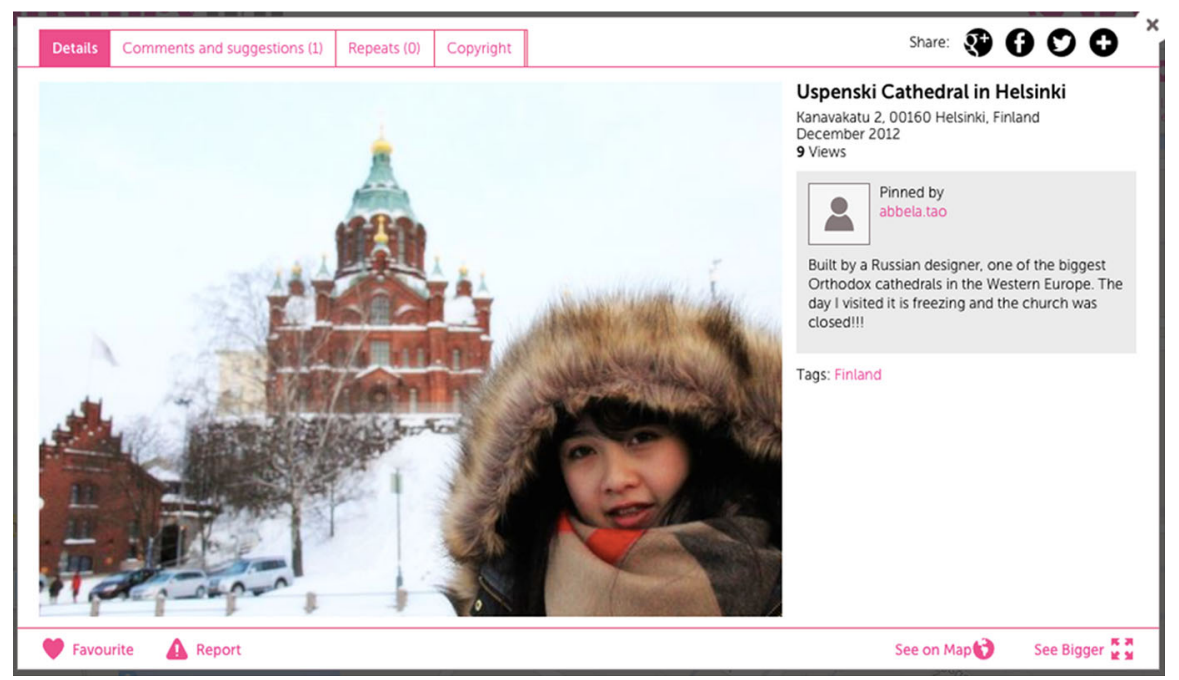

Fig. 7 Uspenski Cathedral in Helsinki. (C) 2013 Han Tao. Added to Historypin: Sat 19 Oct 2013. https:// www.historypin.org/en/person/50442/explore/geo/60.168365,24.957933,2/bounds/-24.177699,-39. $553786,84.741321,89.469652 / \mathrm{pin} / 182366$. Accessed 10 Oct 2016 
the same time the photograph was taken and is not a later addition to the photograph. Even if it is not taken by her, it has the appearance of a selfie:

In the aesthetics conventions of the camphone self-portrait the prominent rhetorical forms and style are characterized by the intimate, lowbrow frontal headshots taken at arm's length (Lüders et al. 2010, p. 959).

The picture forms part of a social media discourse, without which it is not possible to understand the image and its mode of address. Historypin is itself a social media site, albeit with far fewer members than Facebook. This image and other recently taken images challenge the notion of history prevailing in Historypin, which usually targets more distant history. It is the only photograph in my selection that might have been taken with Historypin in mind. The description starts out in the genre of a guidebook, telling us facts about the cathedral, but the second sentence tells about the pinner's experience of the visit. Judging from the text only, this image could have been a postcard, but the image does not match the postcard genre. The status update on Facebook can be regarded as a genre (Lomborg 2014), and this example shows how one of the genres it builds upon for its textual expression is the postcard, where the limited space taught people how to write succinct, semi-public messages.

\section{The personal voice}

The examples above have served to illustrate the diversity of personal voices that exist in an archive such as Historypin. The personal voice can emulate, tweak and develop existing genres, among them the archival description, but although emergent genres can be discerned, there is not yet a consistent genre that can be called the "online photo archive" or "Historypin" genre. The frequent use of deictic markers and gestures such as "Here we have Fratton Road", "My dad", "my new Box Brownie", "the day I visited", "We used to" and "This is my primary school photo" is also characteristic of the personal voice as is the egocentric perspective, the subjective statements like "the day I visited it is freezing" (Fig. 7) and the inclusion of value judgments as in Fratton Road (Fig. 2).

Whereas the archival descriptions authored by institutional staff mostly denote the content of the photographs, the descriptions of the photographs pinned by private persons in Historypin speak about the motifs of the photographs as well as of the circumstances under which the photographs were taken. In contrast to the institutional staff, private persons are mostly writing about their own pictures, either photographs they have taken themselves or photographs of themselves or their relatives or places where they have lived. Of the logico-semantic terms of expansion, enhancement and elaboration seem to best characterize the texts that accompany the pictures.

The personal voice can be expressed in the form of a photograph that is not personal or associated with a specific person from the start, like a postcard, but where the text in combination with the mark transform it into a personal document. It is analogue to the physical postcard, a mass-produced printed matter that becomes 
personalized when complemented with a written message and sent to an addressee. When a postcard is reproduced and published in an open photographic archive like Historypin, it can reach a much larger and undefined audience. In the case of Tahunanui Beach (Fig. 6) both the text and the circle drawn on the picture contribute to the creation of the personal voice. Since it is an aerial view, what can be discerned in the circle is a part of the beach, but in a very reduced scale. Even if the scale was larger, we would not see the pinner and his friends partying. It is left to our imagination to conjure up the scenes that were enacted there in 1965.

This is one of the things that set the personal voice apart from the institutional voice: it tells us all sorts of things that are not necessarily visible in the pictures themselves. In semiotic terms, the institutional voice tells us what the picture denotes, whereas the personal voice conveys connotations and information about circumstances and events connected to the picture that the viewer cannot possibly know. Such is the case of Angelo's first year (Fig. 4), where we get to know what the teacher told his pupils in 1933. Another case is St Albans Cathedral (Fig. 3) where we are told that this was the first photograph that the pinner took with her new camera.

The personal voice is not construed according to the recipe "take a photo-then add text". The personal voice can be integrated in the image itself, as the case of more baseball (Fig. 5) and Uspenski Cathedral (Fig. 7), where the narrator is visible.

\section{Conclusion}

Genres that have developed long before the advent of the web serve as patterns for the contributions to Historypin, and at the same time these genres undergo a renewal by being used in this context. One major difference between the institutional and the personal voice is that, unlike the personal voice, the institutional voice does not intend to show and tell about photographs to an audience-it is designed to convey information to users who are searching for and retrieving records in an archive. In the literature addressing the potentials of new technologies for the accessibility of archival material, MacNeil discerns "a shift from record-centric to user-centric models of delivery" (2012, p. 487). Standardization and searchability will still be the guiding principles of cataloguing, and emerging genres will not necessarily eclipse traditional archival values.

Archivists belong to a discourse community versed in the art of authoring archival descriptions and finding aids, but the general public does not. The aim of Historypin is to support communities and enable them to engage in local history, but although Historypin has many traits of a social media site, it does not form one coherent online community. Comments on other peoples' pictures are scarce and what the pinners do is contribute their pieces of a jigsaw puzzle to the map, or their blocks to the quilt. The resulting "bigger picture" will not be the same as the archive as we know it. There are plenty of amateur photographs and snapshots in established archives, and there are many contributions made by private persons to such archives (that have asked the public for help) adding or correcting information 
about the photographs. The resulting records are still under institutional control, whereas in Historypin, the personal voice has gained a further degree of freedom, as the site lets people speak about their own pictures. The amount of freedom is of course debatable, since the organization behind Historypin maintains control with the help of several means-general information, guidelines, launching of themes and not least, the concept of the map as the main organizing principle of the content. The layout of the interface in the examples in this article recalls a physical archival record, which give all contributions, institutional as well as private, an institutional frame and thus gives priority to the creation of the institutional voice. Nevertheless, the development of platforms for open archives such as Historypin might entail the increased democratization that Myers and Hamilton (2015) envisage for the writing of history in the context of social media and the constant renewal of genres that occurs there.

The fact that people speak about their own pictures makes the concept of deixis especially useful. Drawing on the examples above, a possible variety of showingpointing that might occur in Historypin or other web-based media is the combination of linguistic markers like "this", "here we see" with visual markers such as images of hands holding photographs and marks such as circles and crosses, as summarized in Table 1. Both the categories linguistic and visual markers are open, and although I have identified two types of visual markers here, further types could be added.

It is not unlikely that Historypin users would learn from each other and take up strategies for communication they discover when browsing the site. Combinations would mean a more vigorous application of deixis and make the personal voice stronger, blurring the border between oral and written modes along the line of Ong's concept of secondary orality. The visual markers would not only make the photographs into personal documents, it would effectively destroy the illusion of the photograph as a transparent window and, therefore, emphasize the objecthood of the photograph.

The deictic gesture also has a temporal aspect; it points to a picture that exists in the present, what the image is presently showing, but the events shown in the photograph happened in the past. A description such as "This is a picture that shows how we used to...." contains a temporal tension, as it requires the reader to simultaneously apply two parallel time perspectives. Furthermore, the photograph is taken at a certain point in time, but the stories it gives rise to is not limited to that moment. The accompanying story/description can make the photograph extend its time span, from an instant to a longer duration of time.

Table 1 Deixis of the personal voice. One or more of the markers above can occur in one post, creating layers of deixis

\begin{tabular}{|c|c|c|}
\hline $\begin{array}{r}\text { Linguistic } \\
\text { markers }\end{array}$ & This, My, Here, We & $\begin{array}{l}\text { Figures } 2,3,4 \text {, } \\
\quad 5,6,7\end{array}$ \\
\hline \multirow[t]{2}{*}{$\begin{array}{l}\text { Visual } \\
\text { markers }\end{array}$} & $\begin{array}{l}\text { Part of body, e.g. hand, of the person showing the photograph visible in } \\
\text { the picture }\end{array}$ & Figure 5 \\
\hline & $\begin{array}{l}\text { Pointers such as circles, arrows or crosses added to the surface of the } \\
\text { photograph emphasizing certain elements of the picture }\end{array}$ & Figures 4,6 \\
\hline
\end{tabular}


A consequence of an archive such as Historypin might be a change in the appraisal of photographs. Archiving guidelines can contain recommendations for how to deal with the dilemma of the huge amounts of photographs waiting to be digitized or catalogued and the insufficient staff hours available for performing this work. Family snapshots and unidentified portraits are examples of categories that are of lower value for researchers. The guidelines for efficient archival processing in the University of California Libraries state:

However, some kinds of photographs occur in great volume and have lower value than others: family snapshots and portraits; unidentified portraits; and voluminous and repetitive files of negatives and/or contact sheets. These are good candidates for efficient processing techniques. (2012, p. 40)

Through being exposed in Historypin and other similar open archives, the hitherto lowly valued photographs might increase in value thanks to the personal voice that supports them. A subjective opinion, as we saw in Fratton Road above, can be seen as an expansion adding value to the image by introducing the perspective of the inhabitants of the place it concerns. The photographs in Historypin show much more than what can be seen in the original pictures alone. Not only do these photographs and their descriptions tell personal stories, they tell the story of photography and photographic practices; how and with what technique photographs have been created, how they are collected and shown.

The two voices run in parallel in Historypin, but could they meet? Could institutions engage skilled writers who create fictional stories, based on images in the archive, emulating the personal voice in order to convey the contents of their archive to a larger audience? Fictionalizing archives has long been an artistic strategy resulting in works exhibited in art galleries (see for example The Atlas Group (n.d.)), but would it be possible to encompass this strategy within the archive, without confusing the user and jeopardizing the credibility of the institution? This might be a dangerous path to tread, but potentially rewarding and one that would merit further research.

Open Access This article is distributed under the terms of the Creative Commons Attribution 4.0 International License (http://creativecommons.org/licenses/by/4.0/), which permits unrestricted use, distribution, and reproduction in any medium, provided you give appropriate credit to the original author(s) and the source, provide a link to the Creative Commons license, and indicate if changes were made.

\section{References}

The Atlas Group (n.d.) Artistic project. http://www.theatlasgroup.org. Accessed 13 Oct 2016

Baggett M, Gibbs R (2014) Historypin and Pinterest for digital collections: measuring the impact of image-based social tools on discovery and access. J Libr Adm 54(1):11-22

Bakhtin MM (1986) The problem of speech genres. In: Emerson C, Holquist M (eds) Speech genres and other late essays. University of Texas Press, Austin, pp 60-102

Bal M (1991) Reading "Rembrandt": beyond the word-image opposition. Cambridge Univ. Press, Cambridge

Barthes R (1964) Rhétorique de l'image. Communications 4(4):40-51

Bate D (2016) Photography: the key concepts. Taylor \& Francis, London 
Bruns A (2008) Blogs, Wikipedia, Second Life, and beyond: from production to produsage. Peter Lang, New York

Bühler K (1934) Sprachtheorie: Die Darstellungsfunktion der Sprache. G. Fischer, Jena

Chalfen R (1987) Snapshot versions of life. Bowling Green State University Press, Bowling Green

Devitt AJ (2009) Re-fusing form in genre study. In: Giltrow J, Stein D (eds) Genres in the internet. John Benjamins Publishing Company, Amsterdam, pp 27-47

Edwards E (2004) Photographs objects histories: on the materiality of images, ed. with Janice Hart. Routledge, London

Elkins J (1998) On pictures and the words that fail them. Cambridge University Press, Cambridge

Frow J (2007) 'Reproducibles, rubrics, and everything you need': genre theory today. PMLA 122(5): 1626-1634

Frow J (2015) Genre. Routledge, New York

Genette G (1983) Narrative discourse. Cornell University Press, Ithaca

Giaccardi E (ed) (2012) Heritage and social media: understanding heritage in a participatory culture. Routledge, New York

Harkema C, Nygren C (2012) Historypin for library image collections: new modes of access for unique materials at the University of Saskatchewan Library. Partn Can J Libr Inf Pract Res 7(2). https:// journal.lib.uoguelph.ca/index.php/perj/article/view/1970. Accessed 10 Oct 2016

Historypin User Guide (2013). https://s3-eu-west-1.amazonaws.com/wawwd-resources/6.+HP_GUIDE_ 2013.pdf. Accessed 10 Oct 2016

How to Add a Pin to Historypin (2016) Video on how to pin a photo on Historypin through the updated pinning interface. https://www.youtube.com/watch?v=k19wqBMqUwM. Accessed 10 Oct 2016

How to Pin a Photo (2011) Video on how to pin a photo on Historypin. https://www.youtube.com/ watch?t=27\&v=7RWb7nw2q6w. Accessed 10 Oct 2016

ISAD $(G)$ : General international standard archival description: adopted by the Committee on Descriptive Standards, Stockholm, Sweden, 19-22 September 1999 (2000) 2nd edn. ICA, Ottawa. ISBN 0-9696035-5-X. http://www.icacds.org.uk/eng/ISAD\%28G\%29.pdf. Accessed 10 Oct 2016

Kalfatovic M, Kapsalis E, Spiess K, Van Camp A, Edson M (2008) Smithsonian Team Flickr: a library, archives, and museums collaboration in web 2.0 space. Arch Sci 8(4):267-277

Knape J (2013) Modern rhetoric in culture, arts, and media: 13 essays. De Gruyter, Berlin

Kress GR, van Leeuwen T (2006) Reading images: the grammar of visual design, 2nd edn. Routledge, London

Langford M (2001) Suspended conversations: the afterlife of memory in photographic albums. McGillQueen's University Press, Montreal

Levinson SC (2004) Deixis. In: Horn LR, Ward G (eds) The handbook of pragmatics. Blackwell Publishing, Oxford, pp 97-121

Library of Congress (2013) Descriptive cataloging of rare materials (graphics), DCRM(G). http://rbms. info/dcrm/dcrmg/. ccessed 10 Oct 2016

Lomborg S (2011) Social media as communicative genres. MedieKult J Media Commun Res 27(51):55-71

Lomborg S (2014) Social media, social genres: making sense of the ordinary. Routledge, Taylor \& Francis Group, New York

Lüders M, Prøitz L, Rasmussen T (2010) Emerging personal media genres. New Media Soc 12(6):947-963

MacNeil H (2012) What finding aids do: archival description as rhetorical genre in traditional and webbased environments. Arch Sci 12(4):485-500

Martinec R, Salway A (2005) A system for image-text relations in new (and old) media. Vis Commun 4(3):337-371

McNeill L (2005) Genre under construction Language@ Internet 2. http://www.languageatinternet.org/ articles/2005/120

Miller CR (1984) Genre as social action. Q J Speech 70(2):151-167

Mitchell WJT (1996) Word and image. In: Nelson R, Shiff R (eds) Critical terms for art history. University of Chicago Press, Chicago, pp 47-57

Myers C, Hamilton JF (2015) Open genre, new possibilities: democratizing history via social media. Rethink Hist 19(2):222-234

Oliver G, Duff WM (2012) Genre studies and archives: introduction to the special issue. Arch Sci 12(4):373

Ong W (2002) [1982] Orality and literacy: the technologizing of the word. Routledge, London 
Schwartz JM (2002) Coming to terms with photographs: descriptive standards, linguistic 'othering', and the margins of archivy. Archivaria 54:142-171

Scott C (1999) The spoken image: photography and language. Reaktion Books, London

Sinn D, Syn SY (2014) Personal documentation on a social network site: Facebook, a collection of moments from your life? Arch Sci 14(2):95-124

Smithsonian Institution (2010) Basic guidelines for minimal descriptive embedded metadata in digital images by EMDaWG (Embedded Metadata Working Group—Smithsonian Institution). http://www. digitizationguidelines.gov/guidelines/GuidelinesEmbeddedMetadata.pdf. Accessed 10 Oct 2016

Sontag S (1977) On photography. Penguin Books, London

Taylor HA (1987) Transformation in the archives: technological adjustment or paradigm shift. Archivaria 25:12-28

Taylor HA (1988) 'My very act and deed': some reflections on the role of textual records in the conduct of affairs. Am Arch 51:456-469

University of California Libraries (2012) Guidelines for efficient archival processing in the University of California Libraries. http://libraries.universityofcalifornia.edu/groups/files/hosc/docs/_Efficient_ Archival_Processing_Guidelines_v3-1.pdf. Accessed 10 Oct 2016

VeleHanden [ManyHands] https://velehanden.nl/. Accessed 05 Oct 2016

Wagner K (2011) Moblogging, remediation and the new vernacular. Photographies 4(2):209-228

Karin Wagner is a professor in Art History and Visual Studies at the Department of Cultural Sciences at the University of Gothenburg, Sweden. Her research interests include photography, new media, digital culture and visual communication. Recent publications are "Reading packages: Social semiotics on the shelf" in Visual Communication 2015 14.2: 193-220 and "The package as an actor in organic shops" in Journal of Cultural Economy 2013 6.4: 434-452. 